\title{
The Research of Complex System Property between Thermosensitive Polymer and Surfactant
}

\author{
Chao Ma ${ }^{1,2}$, Gang Wan ${ }^{1}$ and Tang Tang ${ }^{1}$ \\ 1. Province Key Laboratory of Oil and Gas Drilling and Production Engineering, College of Petroleum Engineering, Yangtze \\ University, Wuhan 430100, China \\ 2. The State Key Laboratory of Polymer Materials Engineering, Polymer Research Institute of Sichuan University, Chengdu 610065, \\ China
}

Received: March 20, 2015 / Accepted: May 04, 2015 / Published: August 31, 2015.

\begin{abstract}
In this paper, the rigid structural thermosensitive polymer (made in lab) of NBS (N-butyl styrene), N, N-DEAM (diethyl acrylamide) and AM (acrylamide) was prepared. The influence of viscosity for copolymer solution under different reaction conditions such as temperatures and inorganic salt (monovalent salt and divalent salt) was analyzed. The experiment studies the combination of polymer situation and three different types of surfactants under certain conditions of the room temperature $\left(25^{\circ} \mathrm{C}\right)$ and the formation temperature $\left(76^{\circ} \mathrm{C}\right)$. At last, the influence of the surfactant kinds and concentration on the viscosity of the polymer solution are studied. The results show that: The copolymer solution, the apparent viscosity of which decreases with the increasement of temperature, but its viscosity has suddenly increased and thereafter dropped in the transition temperature. So the temperature sensitive effect of copolymer is very significantly. When the concentration of inorganic salt and surfactant can be controlled in certain extent, the copolymer solution, the effect increases with the increasement of the concentration, but the viscosity of which decreases with the increasement of shear rate. Shear rate can be controlled in certain extent, shearing stability properties of the copolymer solution are proved.
\end{abstract}

Key words: Butyl styrene, hydrophobic monomer, solution properties, thermosensitive polymer, surfactant.

\section{Introduction}

Research development of polyacrylamide flooding agent with temperature resistance and salt tolerance is adapted to high temperature and salinity formation for this stringent requirement. In recent years, polyacrylamide has been used as its backbone by domestic and international researchers, with the introduction of hydrophobic monomer, the thermal resistant and salt-tolerant monomer into polymer side chain. The thermal resistant and salt-tolerant monomer is not directly grafted onto the main chain.

It is linked by ester linkage or an ester bond. Pyrohydrolysis of ester linkage or an ester bond is very easy [1-3]. Besides, the nature of the polymer

Corresponding author: Chao Ma, associate professor, research fields: oil-gas chemical teaching and scientific research work. E-mail: mc19790924@126.com. situation has mainly the property of the conventional water soluble polymer by modification. The conventional water soluble polymer solution, the apparent viscosity of which decreases with the increasement of temperature, salt concentration and shear rate. But its viscosity is high enough, shortly afterwards, it is a sharp drop. The nature of copolymer is in a difficult position to satisfy request for adapting the high temperature and salinity formation.

The special phenomenon has shown that, the viscosity of the linear poly N-alkyl acrylamide-based polymer solution increases with the increasement of temperature, salt concentration above the phase low critical solution temperature [4-9]. Its rheological properties were studied in this paper. The influence of viscosity for thermosensitive polymer solution under different reaction conditions such as temperatures and inorganic salt (a monovalent salt and divalent salt) was 
analyzed. The experiment studies the combination of polymer situation and three differential concentration of surfactants. The influence of the surfactant on the viscosity of the polymer solution was studied. It is used as polyacrylamide flooding agent with temperature resistance and salt tolerance.

\section{Experiment}

\subsection{Equipment and Materials}

Thermosensitive polymers (made in lab, code: WM-7), hydrophobically associating polymers: industrial products; Sichuan Guangya Chemical Co, Ltd; sodium chloride. Calcium chloride: analytical pure; Tianjing Fucheng Chemical Regent Factory; sodium dodecyl sulfate; sodium dodecylsulfate. Sodium dodecyl benzene sulfonate: analytical pure; Wuhan Zhongtian Chemical Co, Ltd. Stickness metre: Brookfield DV3T, engineering laboraties, Inc.

\subsection{Methods}

\subsubsection{Temperature Sensitivity of Copolymer}

Thermosensitive polymer solution (WM-7) is made up into two kinds of the different concentrations with distilled water, the concentrations of the preparations are $2,000 \mathrm{mg} / \mathrm{L}$ (low concentration) and $20,000 \mathrm{mg} / \mathrm{L}$ (high concentration). The viscosimeter uses a No. 0 rotor. When the shear rate is $6 \mathrm{r} / \mathrm{min}\left(7.34 \mathrm{~s}^{-1}\right)$, in the range of temperature $\left(40-120{ }^{\circ} \mathrm{C}\right)$, it discussed the viscocity of the copolymer solution, mainly about the temperature sensitivity of thermosensitive polymer.

2.2.2 The Effect of Salt Concentration on the Apparent Viscosity of the Copolymer Solution Has Been Studied

Thermosensitive polymer solution (WM-7) is made up into some of the same concentrations with distilled water, their concentrations are $2,000 \mathrm{mg} / \mathrm{L}$. Then add monovalent salt $(3,000-100,000 \mathrm{mg} / \mathrm{L} \mathrm{NaCl})$ and divalent salt $\left(100-500 \mathrm{mg} / \mathrm{L} \mathrm{CaCl}_{2}\right)$ of different concentrations. The viscosimeter uses a No. 0 rotor. At the temperature of $30^{\circ} \mathrm{C}$ and different shear rate, the influence of salt concentration on the viscosity of the copolymer solution is studied, the paper analyzes the inorganic salt sensitivity of thermosensitive polymer.

2.2.3 The Effect of Surfactant Concentration on the Apparent Viscosity of the Copolymer Solution Has Been Studied

Under certain conditions of the room temperature $\left(25{ }^{\circ} \mathrm{C}\right)$ and the formation temperature $\left(80{ }^{\circ} \mathrm{C}\right)$, thermosensitive polymer solution (WM-7) is made up into some of the same concentrations with distilled water, their concentrations are $20,000 \mathrm{mg} / \mathrm{L}$. The viscosimeter uses a No. 0 rotor. When the shear rate is $6 \mathrm{r} / \mathrm{min}\left(7.34 \mathrm{~s}^{-1}\right)$, the influence of the surfactant kinds and concentration on the viscosity of the polymer solution are studied, including sodium dodecyl sulfate, sodium lauryl sulfonate and sodium dodecyl benzene sulfonate. We compound the surfactant with the copolymer solution, then the influence of which solution on the viscosity of the solution is studied.

\section{Results and Discussions}

\subsection{Temperature Sensitivity of the Copolymer Solution}

As you can see from Figs. 1 and 2: The apparent viscosity of thermosensitive polymer solution $(2,000 \mathrm{mg} / \mathrm{L})$ decreases with temperature increasing. In the range of temperature $\left(76-80{ }^{\circ} \mathrm{C}\right)$, its viscosity has suddenly increased, the initial viscosity of the solution increases from $19 \mathrm{MPa} \cdot \mathrm{s}$ to $39 \mathrm{MPa} \cdot \mathrm{s}$, its viscosity is $20 \mathrm{MPa} \cdot \mathrm{s}$, its phase transition temperature is between $76{ }^{\circ} \mathrm{C}$ and $80{ }^{\circ} \mathrm{C}$. The apparent viscosity of thermosensitive polymer solution $(20,000 \mathrm{mg} / \mathrm{L})$ decreases as the temperature is increased. In the range of temperature $\left(70-76^{\circ} \mathrm{C}\right)$, its viscosity has increased, but the increase is not larger, its phase transition temperature is between $70{ }^{\circ} \mathrm{C}$ and $76^{\circ} \mathrm{C}$. Thus it can be seen. In the range of certain temperature, the increasement of the apparent viscosity of two solutions is a phenomenon. Thermal property of low concentration of thermosensitive polymer solution is more obvious, the viscosity increase of low concentration of thermosensitive polymer solution is larger. The viscosity increase of high concentration of 


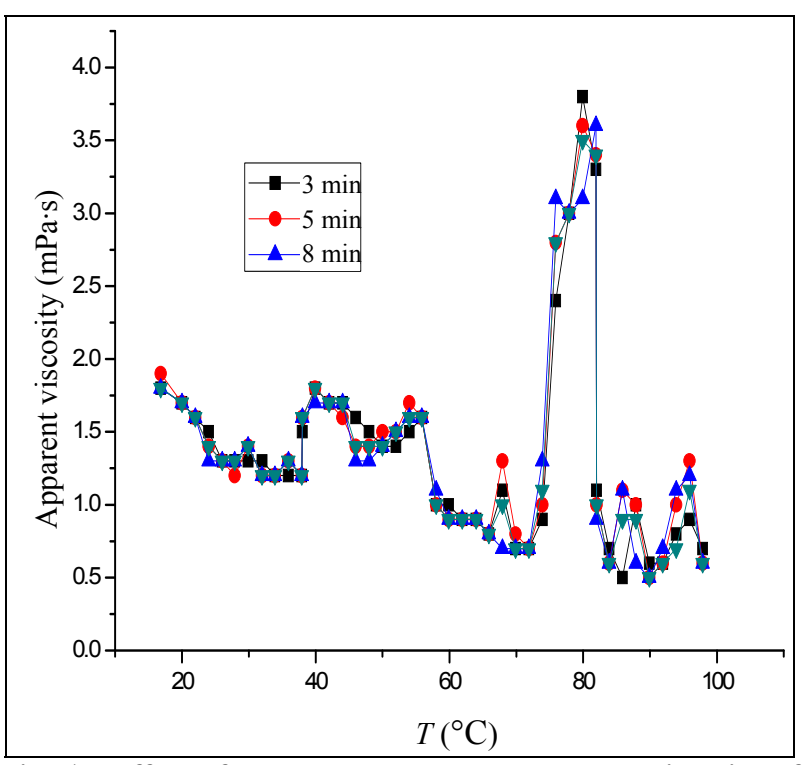

Fig. 1 Effect of temperature on the apparent viscosity of the solution $(2,000 \mathrm{mg} / \mathrm{L})$.

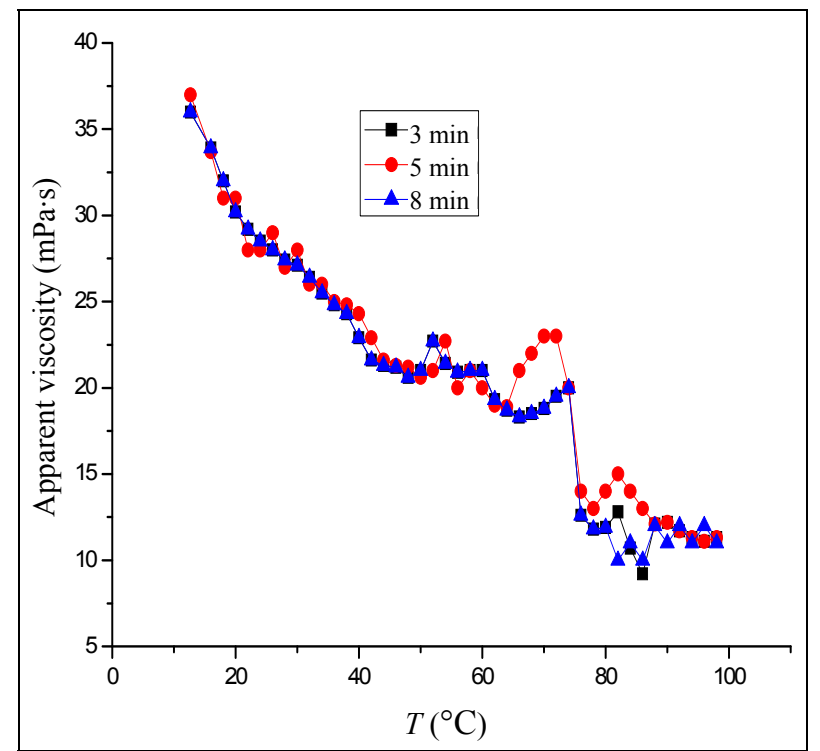

Fig. 2 Effect of temperature on the apparent viscosity of the solution $(20,000 \mathrm{mg} / \mathrm{L})$.

thermosensitive polymer solution is slight. When viscosity increases, its phase transition temperature decreases. The reason of the increase of viscosity for this lies in hydrogen bond association. A dilute solution has not enough these hydrogen bonds. When the temperature increases in certain extent, the molecules collide even intense, hydrogen bond association is created by the collision of the molecules [10]. Concentrated solution has a great many molecular chains. Part of hydrogen bonds has been associated, when the temperature increases, the molecules move faster and hydrogen bonds associate easier [11].

\subsection{The Effect of Inorganic Salt on the Apparent Viscosity of the Copolymer Solution}

As you can see from Fig. 3, the concentration of monovalent salt increases from $1,000 \mathrm{mg} / \mathrm{L}$ to $100,000 \mathrm{mg} / \mathrm{L}$. Under the low shear rate $(50 \mathrm{rpm}$, $100 \mathrm{rpm}$ ), the viscosity increase of low concentration of thermosensitive polymer solution is slight. Under the high shear rate (150 rpm, $200 \mathrm{rpm}, 250 \mathrm{rpm})$, the viscosity increase of high concentration of thermosensitive polymer solution is larger. As you can see from Fig. 4, at a low or high shear rate, the viscosity of copolymer solution increases with the concentration increases of $\mathrm{CaCl}_{2}$ concentration. The viscosity of the copolymer solution increases with the increasement of the experimental shear rate. On the whole, the viscosity of the thermosensitive polymer increases in high salt condition. Conventional polyacrylamide solution has not the particularities of the thermosensitive polymer. Thus, the viscosity of the thermosensitive polymer increases in high salt condition.

\subsection{The Effect of Surfactant Concentration on the Apparent Viscosity of the Polymer Solution}

As you can see from Fig. 5, at the temperature of $25{ }^{\circ} \mathrm{C}$, the copolymer solution, the apparent viscosity of which decreases with the increasement of surfactant concentration, but its viscosity has slowly increased. The apparent viscosity reaches a maximum and then drops down. Because of three kinds of the surfactants as anionic surfactants have been widely applied in the field of flooding agent. The hydrophobic group of anionic surfactant interact with the hydrophobic group of the copolymer solution to provide a linkage point of hydrophobic association [12]. Thus the viscosity of copolymer solution increases. The anionic surfactant is negatively charged, what increase the negatively charged group of molecular chains by hydrolysis. Electrostaic repulsion is formed by the interaction, which led to the viscosity increases. 


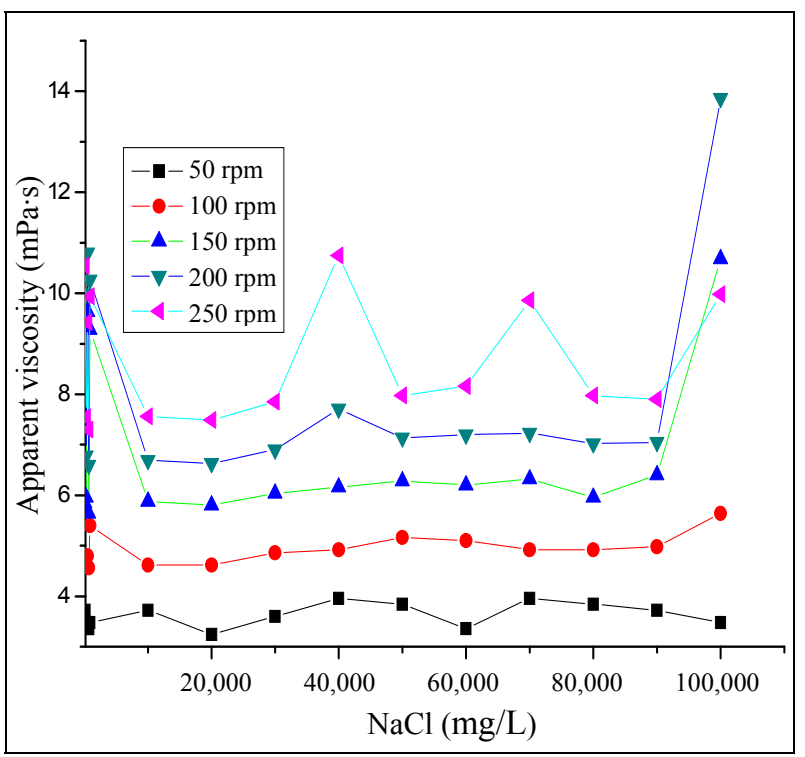

Fig. 3 Effect of $\mathrm{NaCl}$ concentration on the apparent viscosity of the solution $(2,000 \mathrm{mg} / \mathrm{L})$.

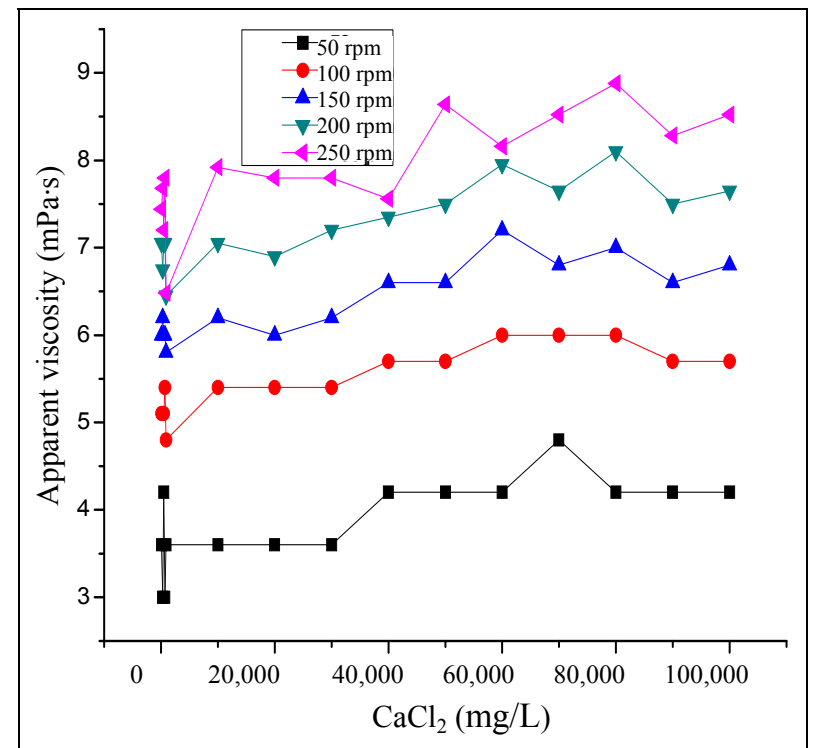

Fig. 4 Effect of $\mathrm{CaCl}_{2}$ concentration on the apparent viscosity of the solution $(20,000 \mathrm{mg} / \mathrm{L})$.

The solution begins to form a large number of micelles when the surfactant concentration continues to increase. Hydrophobic groups are wrapped in micelles. Because of associating partial hydrophobic groups decrease, the associating interaction of hydrophobic groups weaken, and the link between the molecules is destroyed [13]. The crosslinking network structure and the viscosity of the solution have suddenly increased. When the concentration of surfactants are the same, the influence sequence of surfactants on the apparent

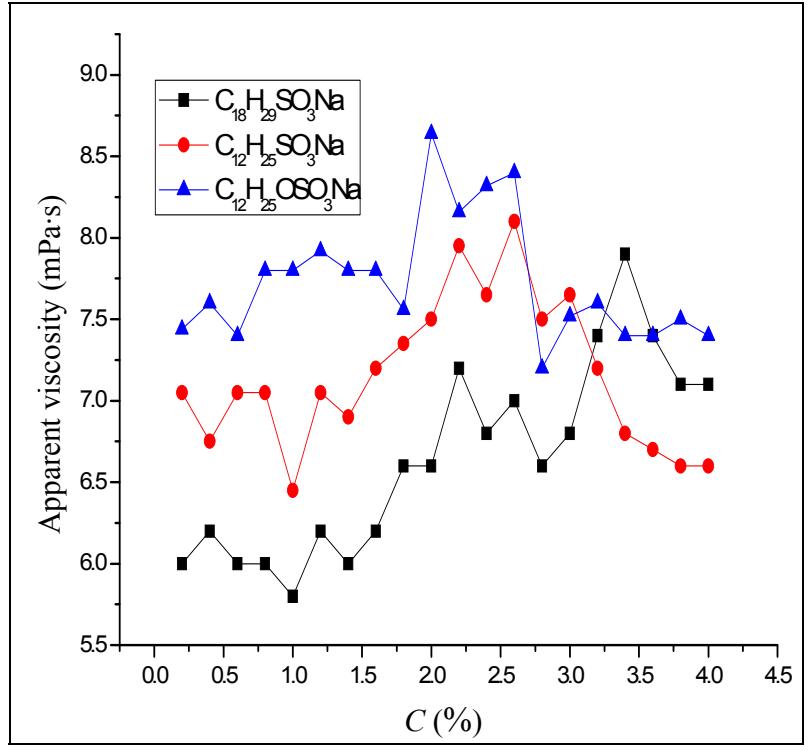

Fig. 5 Effect of surfactant on the apparent viscosity of the solution $\left(25^{\circ} \mathrm{C}\right)$.

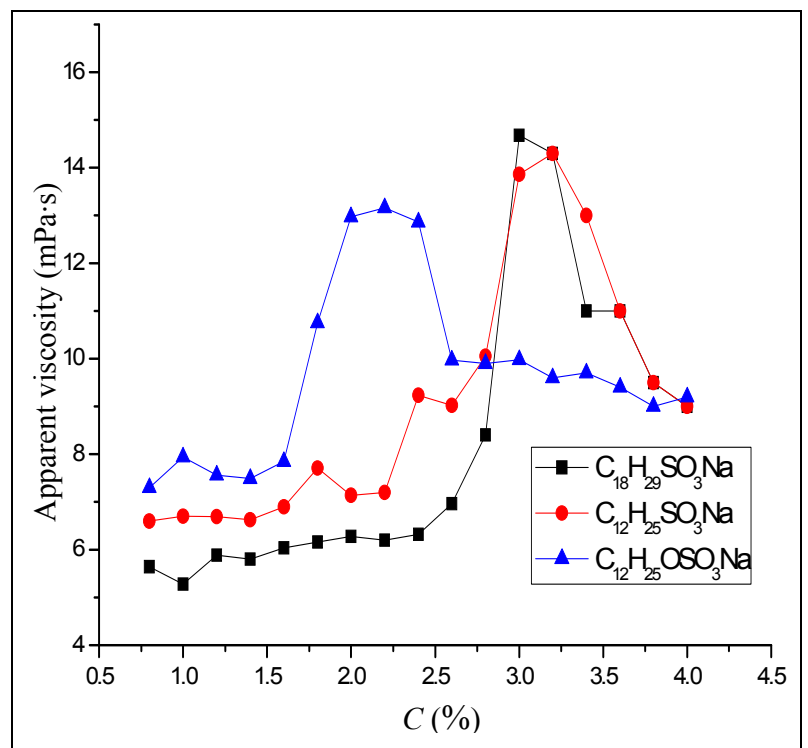

Fig. 6 Effect of surfactant on the apparent viscosity of the solution $\left(76^{\circ} \mathrm{C}\right)$.

viscosity of the solution is sodium dodecyl sulfate $>$ sodium lauryl sulfonate $>$ sodium dodecyl benzene sulfonate, the viscosity of the copolymer solution is related with the structure of the surfactant. As you can see from Fig. 6, the solution viscosity in the low temperature $\left(25^{\circ} \mathrm{C}\right)$ and the high temperature $\left(76^{\circ} \mathrm{C}\right)$ have similar rules. Apparent viscosity increases more evident with the increment of the low temperature. It is mainly because raising the temperature can enhance the association. 


\section{Conclusions}

At a low or high shear rate, the viscosity of copolymer solution increases. The viscosity of the copolymer solution increases with the increasement of the experimental shear rate. On the whole, the viscosity of the thermosensitive polymer increases in high salt condition.

The apparent viscosity of thermosensitive polymer solution decreases with shear rate increasing. In the range of the shear rate (10-30 $\left.\mathrm{s}^{-1}\right)$, its viscosity has a sharp drop. It has the character of shear thinning. When the shear rate is $40 \mathrm{~s}^{-1}$, the viscosity of the copolymer decrease is not larger, which remains generally stable. In the formation of a shear, rate is $100-170 \mathrm{~s}^{-1}$. Thermosensitive polymer has a good shearing resistant capability.

At the temperature of $30^{\circ} \mathrm{C}$, the copolymer solution, the apparent viscosity of which decreases with the increasement of surfactant concentration, but its viscosity has slowly increase. The apparent viscosity reaches a maximum and then drops down. When the concentration of surfactants are the same, the influence sequence of surfactants on the apparent viscosity of the solution is sodium dodecyl sulfate $>$ sodium lauryl sulfonate $>$ sodium dodecyl benzene sulfonate, the viscosity of the copolymer solution is related with the structure of the surfactant. The solution viscosity in the low temperature $\left(25^{\circ} \mathrm{C}\right)$ and the high temperature $\left(76{ }^{\circ} \mathrm{C}\right)$ have similar rules. Apparent viscosity increases more evident with the increment of the low temperature.

\section{Acknowledgments}

Supported by the Natural Science Foundation of China, salt/thermo induces synthesizing polymer and thickening of the solution with the rigid hydrophobic group (No. 51404036).

Supported by PetroChina Innovation Foundation, temperature/salt sensitivity of the copolymer solution and thermo induce synthesizing the thermal resistant and salt-tolerant polymer (No. 2013D-5006-0207).

\section{References}

[1] Fevola, M. J., Bridges, J. K., Kellum, M. G., Hester, R. D., and McCormick, C. L. 2004. "pH-Responsive Polyzwitterions: Acomparative Study of Acrylamide-Based Polyampholyte Terpolymers and Polybetaine Copolymers." Journal of Applied Polymer Science 94 (1): 24-39.

[2] Xiangjun, L., Kun, L., Shaohua, G., Zhongbin, Y., Lixi, L., and Jing, H. 2013. "Synthesis and Evaluation of Temperature-Resistance and Salt-Tolerant Copolymer (AM-AMPS-DMDAAC-NEA) as Clay Stabilizer." Chemical Research and Application 25 (6): 857-61.

[3] Gao, B. Y., Guo, H. P., Wang, J., and Zhang, Y. 2008. "Preparation of Hydrophobic Association Polyacrylamide in a New Micellar Copolymerization System and Its Hydrophobically Associative Property.” Macromolecules 41 (8): 2890-7.

[4] Yang, X. W., Shen, Y. D., and Li, P. Z. 2010. "Intrinsic Viscosity, Surface Activity, and Flocculation of Cationic Polyacrylamide Modified with Fluorinated Acrylate." Polym Bull 65 (2): 111-22.

[5] Wensheng, C., Qingquan, Z., and Xi, X. 1996. “A Study on Synthesis and Properties of AM-DEAM-AA Copolymer." Polymer Materials Science and Engineering 12 (5): 47-52.

[6] Xiaofei, Z., Li, Z., Li, Z., Xi, Z., and Hua, D. 2007. "Study on the Aqueous Solution Properties of Temperature-Sensitive Water-Soluble Polymer P(NIPAM-HEMA-AM) and P(NIPAM-HEMA-AM-AA).” Polymer Materials Science \& Engineering 23 (3): 85-91.

[7] Huahua, M., Yinyan, G., Zaiqian, S., Shuhua, S., and Xiao, C. 2008. "Thermo-Sensitivity of N-Isopropylacrylamide Copolymers Containing Hydrophobic Units." Journal of Functional Polymers 21 (4): 432- 6 .

[8] Jinqiang, L., Fang, Z., Jianzhong, S., Yongqiang, L., and Qinguo, F. 2009. "Preparation of PNIPAm Grafited Cotton and Its Thermal Sensitivity." Acta Polymerica Sinica 9 (12): 1226-72.

[9] Yanyun, C., and Zhiyi, Z. 2010. "Preparation and Properties of Linear PNIPAM." Insulating Materials 43 (3): 24-8.

[10] Mingzhu, Y., Guangsu, H., and Yong, Z. 2010. "Property Study on Novel Thermo-Sensitive Polyacrylamide Derivatives." China Plastics Industry 40 (4): 35-8.

[11] Xiaofei, Z. 2007. "Study on the Synthesis and Properties 
of Thermo-Sensitive Water-Soluble Polymer Based on 3-Isopropenyl-a,a-Dimethylbenzyl Urethane.” Master thesis, Polymer Research Institute of Sichuan University.

[12] Huanxia, W., Shouxin, L., Yu, F., Xiaoyu, H., and Feng, Z. 2006. "Study on the Synthesis and Properties of Temperature-Sensitive N-Isopropylacrylamide
Copolymer." Master thesis, Polymer Research Institute of Sichuan University.

[13] Huanxia, W., Shouxin, L., Yu, F., Xiaoyu, H., and Sa, Z. 2009. "Synthesis of Poly (N,N-Diethylacrylamide) and the Effect of Salts on the Thermosensitivity of Its Aqueous Solutions.” Acta Physico-Chimica Sinica 25 (9): 1911-5. 